\title{
Mechanical characterization of thin injection-moulded polypropylene specimens under large in-plane shear deformations
}

DOI:

10.1016/j.polymertesting.2018.06.010

\section{Document Version}

Accepted author manuscript

Link to publication record in Manchester Research Explorer

Citation for published version (APA):

Codolini, A., Li, Q. M., \& Wilkinson, A. (2018). Mechanical characterization of thin injection-moulded polypropylene specimens under large in-plane shear deformations. Polymer Testing, 69, 485-489.

https://doi.org/10.1016/j.polymertesting.2018.06.010

\section{Published in:}

Polymer Testing

\section{Citing this paper}

Please note that where the full-text provided on Manchester Research Explorer is the Author Accepted Manuscript or Proof version this may differ from the final Published version. If citing, it is advised that you check and use the publisher's definitive version.

\section{General rights}

Copyright and moral rights for the publications made accessible in the Research Explorer are retained by the authors and/or other copyright owners and it is a condition of accessing publications that users recognise and abide by the legal requirements associated with these rights.

\section{Takedown policy}

If you believe that this document breaches copyright please refer to the University of Manchester's Takedown Procedures [http://man.ac.uk/04Y6Bo] or contact uml.scholarlycommunications@manchester.ac.uk providing relevant details, so we can investigate your claim.

\section{OPEN ACCESS}




\title{
Mechanical characterization of thin injection-moulded polypropylene specimens under large in- plane shear deformations
}

\author{
A. Codolini ${ }^{1}$, Q. M. Li $^{1 *}$, A. Wilkinson ${ }^{2}$ \\ "Corresponding author: Tel.:+44 161306 5740; E-mail address: qingming.li@manchester.ac.uk \\ ${ }^{1}$ School of Mechanical, Aerospace and Civil Engineering; ${ }^{2}$ School of Materials; The University of \\ Manchester; Manchester, M13 9PL; United Kingdom
}

\begin{abstract}
The methodology to extract in-plane shear properties have been standardised for polymer-based composite materials. However, no standards have been designed to extract reliable test data for nonfibre reinforced polymers, which can be used to calibrate finite element material models. The quality of the results from three widely used experimental techniques was examined in this study for mineralfilled polypropylene in terms of shear strain distribution, out-of-plane deformations and shear stressstrain curves with the aid of digital image correlation method. The V-Notched Rail test (ASTM D7078) exhibited ultimate fracture of the specimen, but valid shear strain was only obtained for small deformations. For relatively large strains, more reliable shear test data were found for a modified version of ASTM B831: a standard test designed for aluminium but modified for polymers. Although out-of-plane deformations were avoided using aluminium holders, large variability was found in the strain distribution along the shear path. In contrast, the modified Wyoming Iosipescu test (ASTM D5379) exhibited the most robust shear stress-strain results due to consistent shear strain uniformity and low variability during the entire duration of the test.
\end{abstract}

Keywords: In-plane shear, Mechanical characterization, DIC, Mineral-filled polypropylene, Large deformations

\section{Introduction}

In the past decades, the use of polymer materials in the design of safety components for vehicles has increased due to their combination of modulus, yield stress and high toughness [1]. When their structural response is analysed using finite element codes, an accurate constitutive equation is required. Due to the significant stress anisotropy, plasticity laws based on the von Mises theory are no longer suitable to describe the phenomenology of inelastic polymer deformations [2]. Therefore, additional mechanical tests to the classical uniaxial tensile test are required to calibrate advanced material models (e.g. SAMP-1) which introduced shear test data to characterise non-linear plasticity [3].

Since it is very difficult to induce a stress state of "pure shear" for large deformations in thin sheet components due to unwanted effects, such as out-of-plane deformations, significant effort has been applied in the design of tests to ensure the testing section is "shear dominated" in order to extract reliable material shear data. Numerous specimen geometries and testing fixtures have been proposed to characterise the shear response of polymers; such as the simple shear test [4], Iosipescu shear test [5-7], V-notched rail shear test [8-10], and the two-rail [11] and three-rail shear tests [12]. Several methodologies have been adopted in international standards to measure the shear strength and modulus of polymer composites reinforced by high-modulus fibres. However, no standards are designed to extract the shear behaviour of thin sheets of solid polymers under large deformations. Several studies have been attempted to apply currently available testing methods to injection moulded 
polymers to find out which testing method can be applied to plastics subjected to large shear deformations. Daiyan et al. [13] conducted the modified Wyoming Iosipescu (ASTM D5379) [7] and the V-Notched Rail test (ASTM D7078) [10] on different talc-filled polypropylene compounds together with digital image correlation (DIC). It was observed that the D5379 method introduced less misalignment, and therefore, producing better strain uniformity between the notches. The ASTM D7078 method allowed larger strains under shear stress, which is better suited for stiffer materials. Nunes [14] proposed a modification of the ASTM B831 [15], a standard testing method for thin aluminium alloy specimens, by adding a fixture plate in order to reduce the out-of-plane distortions during shear tests. Since there are a number of sources of uncertainties in finite element simulations for obtaining high quality and reliable material testing data [16], a shear methodology that minimises the non-uniform strain distributions during the experiment needs to be identified, hopefully from the existing tests.

This study is aimed at identifying the most robust shear test methodology that can be used to determine the shear stress-strain curves until failure for thin injection-moulded plaques of a polymer material, in this case polypropylene. Therefore, the mechanical response of thin-walled structures can be more accurately predicted using FE codes. The V-notched rail shear test, the V-notched beam test and the slotted shear test modified by Nunes [14] are analysed by using DIC to identify the methodology that can produce a uniform stress state up to large strains.

\section{Methodology}

\subsection{Material}

The specimens used for the experimental investigation were machined from injection-moulded plaques made of mineral-filled polypropylene. A CNC milling machine was used to cut the desired geometries in order to reduce uncertainties on the material test data derived from damaged samples [17].

The shear test methods analysed in this paper were based on two standard tests for composite materials, i.e. the V-Notched Rail standard (ASTM D7078) and the V-Notched Beam standard (ASTM D5379) (known also as the modified Wyoming Iosipescu test). In addition, the slotted shear ASTM B831 test modified by Nunes [14] was also investigated because it was successfully applied to a polymer material PTFE. In this study, the capability to measure the mechanical shear behaviour of polypropylene is assessed.

Test pieces with the nominal dimensions shown in Fig. 1 were cut from the centre of $3.15 \mathrm{~mm}$ thick, $150 \mathrm{~mm}$ wide and $250 \mathrm{~mm}$ long injection-moulded plates as prescribed in ISO 294-5:2013 in order to avoid edge and injection gate effects.

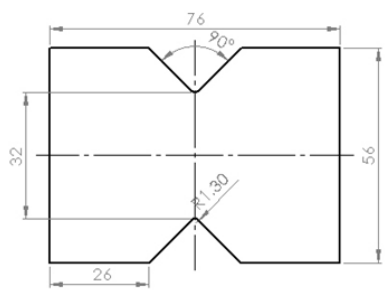

a)

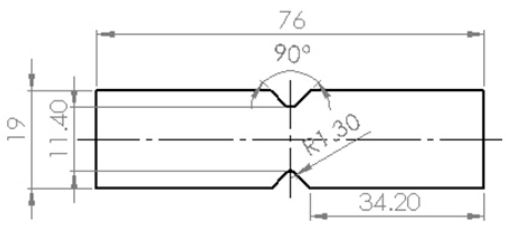

b)

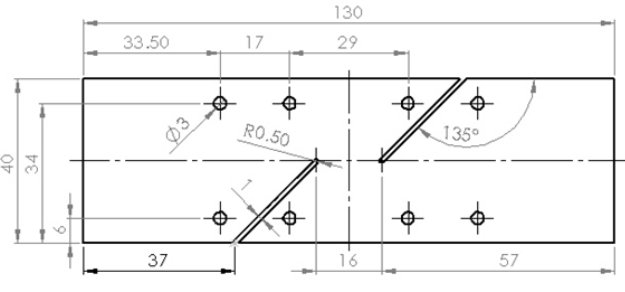

c)

Figure 1 Shear specimens produced: a) ASTM D7078; b) ASTM D5379; c) ASTM B831 modified by Nunes [14]. All dimensions in $\mathrm{mm}$. 
A random speckle pattern was applied to the surface under investigation to allow the correct working of the DIC algorithm. In calculating corresponding points between subsequent images taken by the imaging device, and for correlation between cameras in stereoscopic systems, black and white Plastikote Super Matt paints were used. To improve the accuracy of the strain analysis, specimens with speckle size larger than $2 \mathrm{~mm}$ for ASTM D7078 and $1 \mathrm{~mm}$ for ASTM D5379 and ASTM B831 were discarded.

\subsection{Experiment apparatus}

The three fixtures shown in Fig. 2 were used to test the machined specimens presented in Fig. 1. The D7078 experiment uses a fixture with two separate halves, one connected to each side of the test piece. The sample is fastened between the two blocks in each half of the fixture using three bolts and during the test one side is pulled upward. In the D5379 test, the force is transmitted to the specimen by edge loading, again using a fixture with two separate halves, one connected to each side of the test piece. In Fig. 2b, the left half fixed the sample while the right half of the fixture is forced down, sliding on a bearing post. For the modified B831 test, the commonly used uniaxial tensile test grips were used with a fixture with two separate halves, comprising four $1.5 \mathrm{~mm}$ thick aluminium holders (designed by Nunes [14]) tightened to the specimen. The top half was pulled at a constant crosshead speed and shear strain was introduced in the centre of the test piece.

The experimental fixtures were mounted in the same electro-mechanical testing machine (fitted with a $10 \mathrm{kN}$ load cell), which was operated in a temperature $\left(23 \pm 2{ }^{\circ} \mathrm{C}\right)$ and humidity $(50 \pm 10 \% \mathrm{RH})$ controlled laboratory. A constant crosshead speed of $2 \mathrm{~mm} / \mathrm{min}$ was used to meet quasi-static test requirement in every test. The force was logged in synchronisation with the image acquisition of the DIC system. The speckle pattern on the specimens provided a way of calculating corresponding points between subsequent images taken by the imaging device. 3D DIC data were post processed using DaVis software from LaVision to measure the 3D deformation field of the speckled surface. A subset size of $13 \times 13$ pixel $^{2}$ was selected to accurately calculate the local shear strain distribution in the material between the two notches.

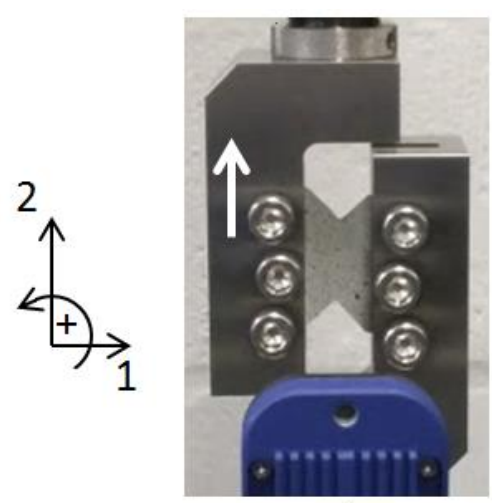

a)

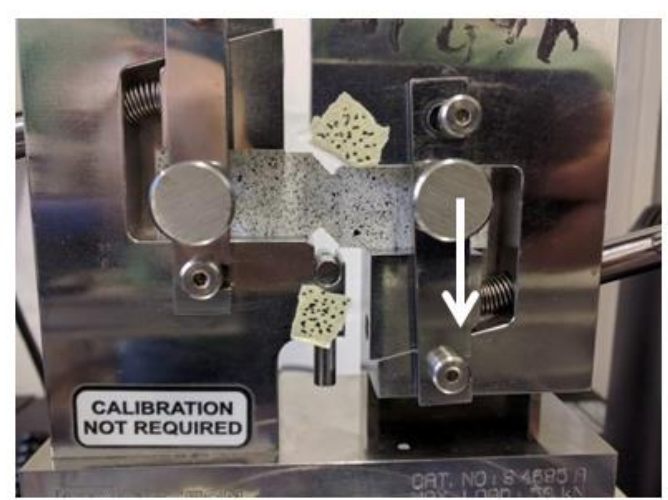

b)

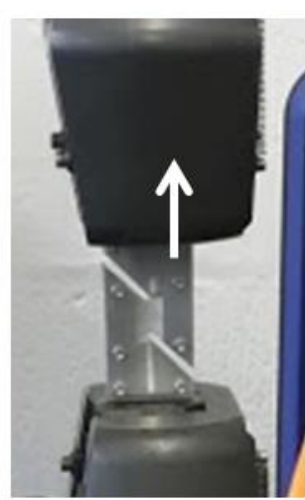

c)

Figure 2 Shear test fixtures used: a) ASTM D7078; b) ASTM D5379; c) ASTM B831 modified by Nunes. All were mounted on the same universal testing machine. White arrows indicate the loading directions of the fixtures.

\subsection{Stress-strain calculation}

When material models are calibrated, true stress-strain curves are required and they are usually derived from the total (elastic and plastic) engineering quantities in the area of interest. In this paper, the nominal stress and strains were extracted at the centre of the specimen (i.e. the original midpoint between the notches).The engineering shear stress was derived from the load cell readings by dividing 
the axial force with the initial cross-sectional area of the gauge section defined as the product of the distance between the two notches with the specimen thickness.

The engineering shear strain was calculated from the DIC measurements by averaging the shear from an area defined by the distance between the two notches with $1 \mathrm{~mm}$ width. The $2 \mathrm{D}$ average shear was derived in terms of the tensorial shear strain components of the infinitesimal strain tensor $\mathbf{E}$ using the follow engineering strain definitions:

$$
\varepsilon_{\text {eng,shear }}=\left(E_{12}+E_{21}\right) / 2 \quad \text { with } E_{i j}=\partial V_{j} / \partial x_{i}
$$

The infinitesimal strain tensor uses the data from the vector $V$ as a function of spatial variables. Since the true and engineering quantities are the same under pure shear condition, from now on no distinction will be made between engineering and true quantities.

\section{Experimental results and discussion}

\subsection{Shear strain distributions}

The main advantage of DIC is its capability to measure the strain field in a wide area that undergoes large deformations. The shear strain distributions in the region between the notches were captured during the three different shear tests and the examples of the results of the software calculations are shown in Fig. 3 for different times during the test duration. 
a) Average Strain $=-0.05$

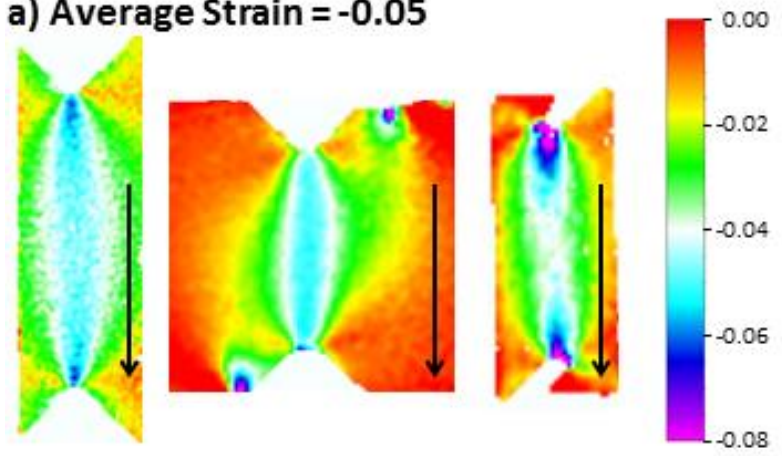

b) Average Strain $=-0.1$

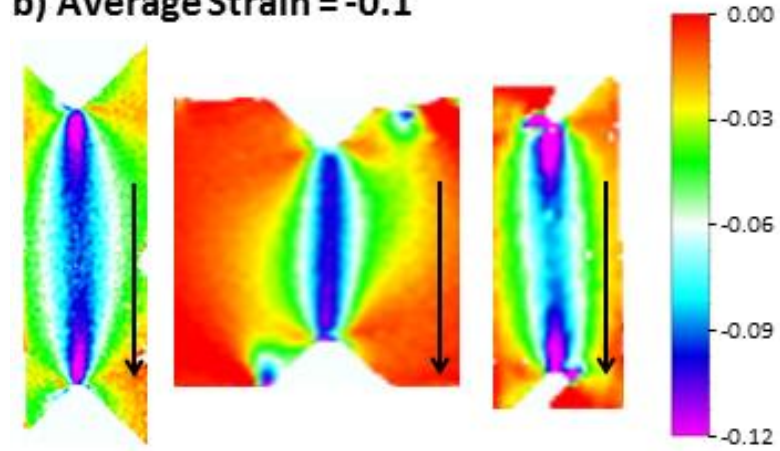

c) Average Strain $=-0.2$

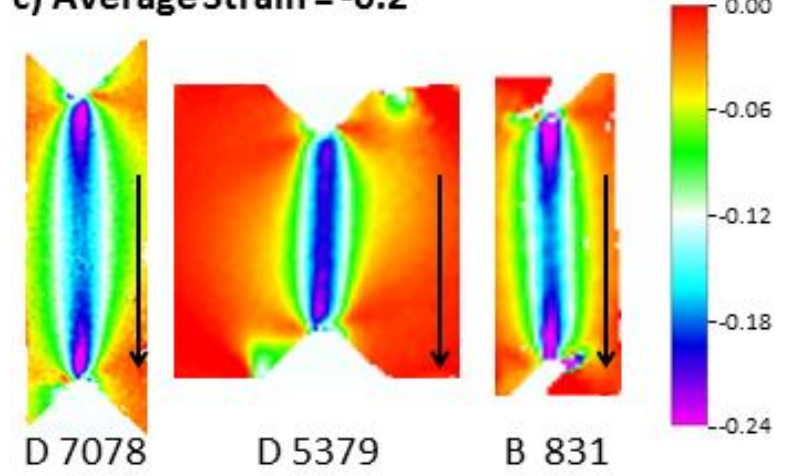

Figure 3 Shear strain distribution of D7078, D5379 and B831 modified tests in the area between the notches at average shear strain: a)-0.05 $\mathrm{mm} / \mathrm{mms} ; b)-0.1 \mathrm{~mm} / \mathrm{mm} ; c)-0.2 \mathrm{~mm} / \mathrm{mm}$. Different scales quantify the evolution of strains during the experiments. Black arrows indicate the loading directions of one half of the specimen.

During each test, one half of the specimen was pulled (indicated by the arrows in Fig. 3) whilst the other was constrained by the test fixture. Due to the existence of the notches, shear strain is concentrated in the region between the two notches of each specimen. The image in Fig. 3 shows that the shear strain is not uniformly distributed along the shear path (i.e. the narrow zone centred around the notch link). For the D7078 and the B831 tests, the images highlight the concentration of shear strain in the proximity of the notches, whereas the image for D5379 showed initially a concentration of strain in the area next to the fixture edges, as observed previously for polypropylene by Daiyan et al. [13]. The ASTM D5379 test exhibited a more uniform shear strain distribution between the notches with a slight clockwise rotation due to a small twist of the specimens during the initial stage of the experiment.

When large shear deformations occurred along the specimens, a loss of strain data due to the detachment of the speckled coating on the specimen was observed for B831 specimens. For D7078 tests, the shear strain was concentrated on the bottom notch. The D5379 specimen was observed to be the only one that maintained good uniformity of strain data along the shear path during the tests. 
The uniformity of shear strain along the line between the notches is analysed for each type of specimen in Fig.4 for the same local shear strain measured at the centre of the shear path.

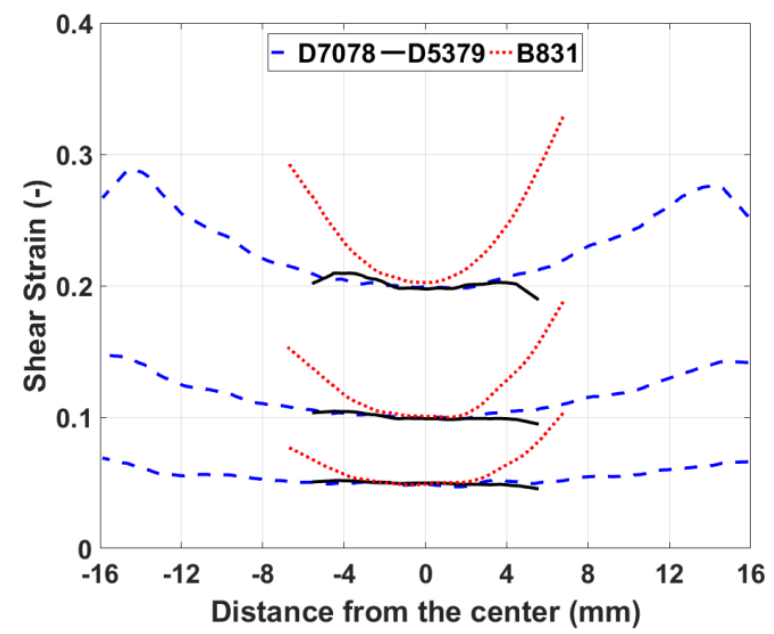

Figure 4 Shear distribution along the shear path at 0.05, 0.1 and 0.2 strain level at the centre of a specimen

As expected, given the geometry of the specimens, the highest values of shear strain were observed in the regions next to the notches and the minimum in the centre of the shear path. D5379 exhibited a very good uniformity of strain along the shear length. In contrast, significant differences were observed between the maximum and minimum values measured along the shear path during the D7078 and D5379 tests as summarised in Table 1.

\begin{tabular}{|c|c|c|c|}
\hline Strain level & D7078 & D5379 & B831 \\
\hline $\mathbf{0 . 2}$ & $0.243 \pm 22.85 \%$ & $0.199 \pm 5.36 \%$ & $0.266 \pm 31.27 \%$ \\
\hline $\mathbf{0 . 1}$ & $0.123 \pm 24.45 \%$ & $0.100 \pm 5.21 \%$ & $0.144 \pm 44.26 \%$ \\
\hline $\mathbf{0 . 0 5}$ & $0.058 \pm 23.35 \%$ & $0.049 \pm 7.02 \%$ & $0.076 \pm 56.70 \%$ \\
\hline
\end{tabular}

Table 1 Shear strain average and standard deviation for the three tests; measured at different strain level at the centre of the specimens

If the average strain was adopted to define the shear level at a specific time during the test, the value can differ from that measured in the centre. By increasing the strain level, the average strain is higher than that measured in the centre for the D7078 and B831 test. The D5379 test resulted in low shear strain variations and more reliable data could be extracted if strain gauges were used within the shear path.

\subsection{Out-of-plane deformations}

The out-of-plane displacement, measured the difference of different instant of time, is considered as another parameter to understand the quality of the shear strain state during the experiment. The smaller the out-of-plane displacement, the closer the testing results to the pure shear.

In contrast to the shear strain distribution, Fig. 5 shows the out-of-plane displacement to be localised in the notched areas only for the D5379 test. For D7078 experiment, significant displacement in the centre of the test piece was observed, indicating the violation of pure shear strain assumption for large deformations. The test fixture and the specimen geometry produced almost zero displacement in B831 test due to the aluminium holder which minimises the effect of fixture misalignments. 


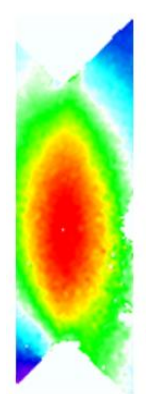

D 7078

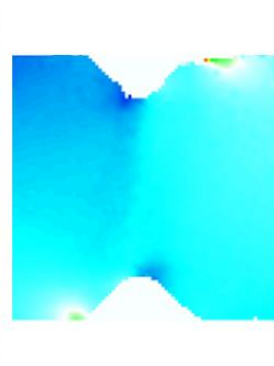

D 5379

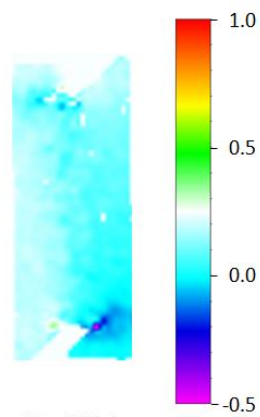

B 831

Figure 5 Out of plane displacement of D7078, D5379 and B831 modified tests at $t=90$ s. Scale is in millimetres

\subsection{Shear stress-strain curves}

The shear stress-strain curves for the three tests were analysed to further understand the quality of the test data because they are generally used to extract the elastic modulus, strength and strain at failure of materials.

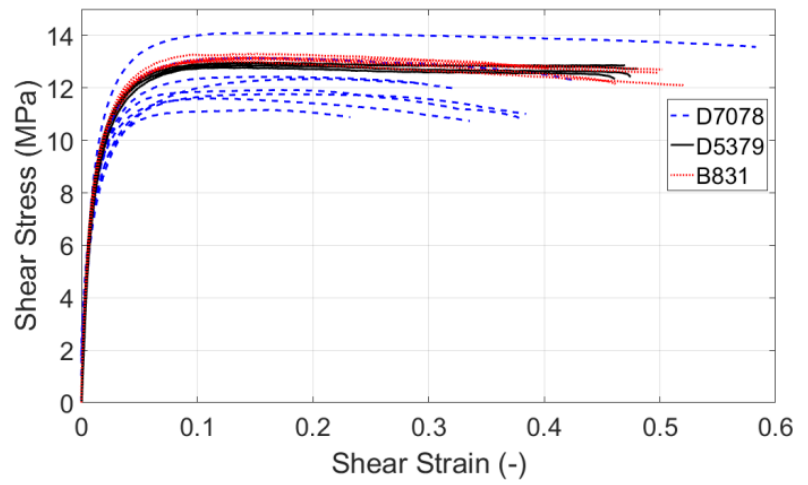

Figure 6 Shear stress-strain curves for the three test fixtures: D7078 (dashed), D5379 (solid) and modified B831 (dotted)

Fig. 6 shows that once plastic strains began in the specimen the gradient of the force curve reduced until the initiation of the instability phenomenon. No further hardening behaviour occurred in any pf the experimental tests until failure. A softening response was observed in several D7078 tests before the complete rupture of the specimen. Fracture of the testing specimen was also observed during the modified B831 tests because there is no limitation to the maximum displacement achievable by the crosshead. No specimen fracture occurred during the D5379 test because the maximum travel distance of the right hand half of the fixture was reached before fracture could occur.

Even though the D7078 test exhibited the largest variability in stress data of the three tests, the maximum stress level did not exceed $14 \mathrm{MPa}$ with a variability of $10 \%$. On the other hand, the D5379 and the B831 experiments showed good repeatability and their maximum stresses have less than $1 \%$ difference among several repetitions.

Ultimate failure during in-plane shear deformations was not observed for all the experiments. Pure shear did not occur during the D7078 test due to significant out-of-plane deformations which produce a multiaxial strain state. The average shear strain at failure of eight repetitions was 0.37 and the standard deviation was $29 \%$. All six modified B831 specimens falied under shear dominant strain state but with a remarkable variability of $15 \%$ for the measured 0.46 average failure strain. Therefore, this experiment is not recommended to determine shear failure strain for polymers. 


\section{Conclusions}

It was found that three types of shear tests produce different shear strain states in the area between two notches for thin Polypropylene samples. The differences are not remarkable during elastic deformations and for small strains. However, when deformation is large, all three testing methods (D7078, D5379 and B831) have problems on shear strain uniformity and repeatability.

Based on these results, the D7078 test is not recommended for measuring shear properties due mainly to its significant out-of-plane deformations and large variability in shear stress-strain curves. The modified B831 test resulted instead in a shear-dominant state until failure and it has the main advantage to avoid the use of complex test fixture. However, the high variability of the shear strains between the two notches makes the modified B831 too sensitive to the calculation of average strain to define the shear stress-strain curve of the injection moulded thermoplastic materials. Although an initial small twist was observed for ASTM D5379 tests, the out-of-plane deformations were limited; a more uniform strain distribution between the notches and a repeatable stress strain results were observed for ASTM D5379 tests. This study concluded that the D5379 test was the most reliable experimental methodology that can be applied to non-fibre reinforced polymers.

\section{Acknowledgments}

The authors express their gratitude to EPSRC and Jaguar Land Rover Ltd. for funding the iCASE research project "Engineering Constitutive and Failure Model of Injection-moulded Polypropylene Filled with Talc Particles". Additionally, the first author gratefully acknowledges the technical support of DIC provided by Dr Mark Quinn, The University of Manchester staff, and the testing support from the National Composites Certification and Evaluation Facility (NCCEF) of The University of Manchester.

\section{Reference}

[1] PlasticsEurope, "Plastics - the Facts 2015," Brussels, 2015.

[2] S. J. Hiermaier, Structures under crash and impact: Continuum mechanics, discretization and experimental characterization. 2008.

[3] S. Kolling, A. Haufe, M. Feucht, and P. A. Du Bois, "SAMP-1: A Semi-Analytical Model for the Simulation of Polymers," in 4th German LS-DYNA Forum, 2005.

[4] D. C. Moreira and L. C. S. Nunes, "Comparison of simple and pure shear for an incompressible isotropic hyperelastic material under large deformation," Polym. Test., no. 32, pp. 240-248, 2013.

[5] N. Iosipescu, "New accurate procedure for single shear testing of metals," vol. 2 (3), pp. 537$566,1967$.

[6] D. F. Adams, "The Iosipescu shear test method as used for testing polymers and composite materials," Polym. Compos., vol. 11, no. 5, pp. 286-290, 1990.

[7] "ASTM D5379. Standard Test Method for Shear Properties of Composite Materials by the VNotched Beam Method," 2012. 
[8] D. O. Adams, J. M. Moriarty, A. M. Gallegos, and D. F. Adams, "The v-notched rail shear test," J. Compos. Mater., vol. 41, no. 3, pp. 281-297, 2007.

[9] M. Gude, W. Hufenbach, M. Andrich, A. Mertel, and R. Schirner, "Modified V-notched rail shear test fixture for sheear characterisation of textile-reinforced composite materials," Polym. Test., vol. 43, pp. 147-153, 2015.

[10] "ASTM D7078. Standard Test Method for Shear Properties of Composite Materials by VNotched Rail Shear Method," 2005.

[11] "ASTM D455. Standard Test Method for In-Plane Shear Properties of Polymer Matrix Composite Materials by the Rail Shear Method," 2007.

[12] I. De Baere, W. Van Paepegem, and J. Degrieck, "Design of a modified three-rail shear test for shear fatigue of composites," Polym. Test., vol. 27, pp. 346-359, 2008.

[13] H. Daiyan, E. Andreassen, F. Grytten, H. Osnes, and R. H. Gaarder, "Shear Testing of Polypropylene Materials Analysed by Digital Image Correlation and Numerical Simulations," Exp. Mech., vol. 52, no. 9, pp. 1355-1369, 2012.

[14] L. C. S. Nunes, "Modified slotted shear test for a thin sheet of solid polymer under large deformations," Polym. Test., vol. 45, pp. 20-30, 2015.

[15] “ASTM B831. Standard Test Method for Shear Testing of Thin Aluminum Alloy Products."

[16] G. Dean and L. Crocker, "Prediction of impact performance of plastics mouldings Part 1: Materials models and determination of properties," Plast. Rubber Compos., vol. 36, no. 1, pp. $1-13,2007$.

[17] A. Codolini, Q. M. Li, and A. Wilkinson, "Influence of machining process on the mechanical behaviour of injection-moulded specimens of talc-filled Polypropylene," Polym. Test., vol. 62, pp. 342-347, 2017. 